\title{
Study of the Blood Count in Hospitalized Patients in the Dermatology Department of the CNAM
}

\author{
Karabinta Yamoussa ${ }^{1,2, ~ *, ~ G a s s a m a ~ M a m a d o u ~}{ }^{1,2}$, Tall Kouressi ${ }^{1}$, Cisse Lamissa ${ }^{1}$, Gnossike Piham ${ }^{1}$, \\ Sanogo Hawa ${ }^{4}$, Dicko Adama ${ }^{1,2}$, Sylla Ousmane ${ }^{1}$, Kodio Mamadou ${ }^{1}$, Bougoudogo Flabou ${ }^{4}$, \\ Faye Ousmane $^{1,2}$, Keita Somita ${ }^{1,2}$, Diallo Dapa ${ }^{2,3}$ \\ ${ }^{1}$ National Support Center for Disease Control (CNAM), Faculty of Medecine and Odontostomatology, University of the Sciences, Technics \\ and Technology, Bamako, Mali \\ ${ }^{2}$ Department of Skin Disease, Faculty of Medicine and Odontostomatology, University of the Sciences, Technics and Technology, Ministry \\ of Higher Education and Scientific Research, Bamako, Mali \\ ${ }^{3}$ Department of Hematology-Oncology at CHU Point G, Faculty of Medicine and Odontostomatology, University of the Sciences, Technics \\ and Technology, Bamako, Mali \\ ${ }^{4}$ Biological Laboratory of the National Institute for Public Health Research, Ministry of Health, Bamako, Mali
}

\section{Email address:}

ykarabinta@yahoo.com (K. Yamoussa)

${ }^{*}$ Corresponding author

\section{To cite this article:}

Karabinta Yamoussa, Gassama Mamadou, Tall Kouressi, Cisse Lamissa, Gnossike Piham, Sanogo Hawa, Dicko Adama, Sylla Ousmane, Kodio Mamadou, Bougoudogo Flabou, Faye Ousmane, Keita Somita, Diallo Dapa. Study of the Blood Count in Hospitalized Patients in the Dermatology Department of the CNAM. American Journal of Laboratory Medicine. Vol. 3, No. 3, 2018, pp. 30-33. doi: 10.11648/j.ajlm.20180303.11

Received: July 3, 2018; Accepted: July 16, 2018; Published: August 15, 2018

\begin{abstract}
The blood count is the biological examination that aims to identify, count and observe the figured elements of the blood. In dermatology, the hemogram is an index of the evolution of the dermatosis and the general state of the patient. The blood count is the refore an examination that is of diagnostic and prognostic value in the management of dermatological conditions. Our objective was to determine the place of the blood count in the management of dermatosis in hospitalized patients of the CNAM. This was a descriptive cross-sectional study of all cases of hemogram performed in all hospitalized patients in the dermatology department of the CNAM during the period from January 1, 2015 to December 31 , 2017, ie 3 years. The inclusion criteria were as follows: all inpatient records containing the hemogram results regardless of age and sex during the study period. Out Of the 133 cases included, 112 had abnormal blood counts, 84.2\% of cases. Females accounted for $51.9 \%$ (69) and males $48.1 \%$ (64). The age of the patients ranged from 2 years to 90 years with an average age of 54.34 years. Among the hematological disorders observed: Anemia accounted for $86.6 \%$ of cases. It was hypochromic and microcytic in $80.4 \%$ of cases, normochromic and normocytic in $16.5 \%$ of cases and macrocytic normochromic in $3.1 \%$ of cases. This anemia was associated with chronic ulceration in almost $100 \%$ of cases, autoimmune bullous dermatosis (Pemphigus and Bullous Pemphigoid) in $72.7 \%$ of cases, erysipelas in $81.8 \%$ of cases, severe toxidermias in $75 \%$ of cases. erythroderma in $60.4 \%$ of cases, cutaneous carcinoma in $87.2 \%$ of cases. Leukocytosis accounted for $59.8 \%$ of cases. This leukocytosis was predominantly neutrophilic in $44.6 \%$ of cases, eosinophilic in $16.5 \%$ and lymphocytosis was observed in $14.6 \%$ of cases. This leukocytosis was associated with chronic ulceration in almost $44.2 \%$ of cases, with autoimmune bullous dermatoses (Pemphigus and Pemphigoid bullosa) in $81.6 \%$ of cases, with erysipelas in $63.6 \%$ of cases, with severe toxidermias in $74.5 \%$ of cases, with erythroderma in $60.2 \%$ of cases, cutaneous carcinomas in $66.3 \%$ of cases. the blood count remains the essential biological examination for the management and monitoring of severe dermatosis requiring hospitalization and our study could be a preliminary to other studies to elucidate its impact on the evolution of the dermatological disease.
\end{abstract}

Keywords: Study of the Blood Count, Hospitalized Patients, Department of Dermatology, CNAM 


\section{Introduction}

The blood count or hemogram $(\mathrm{CBC})$ is the most frequently requested biological examination $[1,2]$. It aims to identify, count and observe the figured elements of the blood [3]. It gives us quantitative and qualitative information about blood cells. In sub-Saharan Africa, where most countries lack a technical diagnostic platform, a well-performed blood count (NFS) is a valuable aid for clinicians. The indications are very numerous and go far beyond the scope of hematological pathologies [4]. It is made from a blood sample collected by venipuncture and collected in a tube containing a dry anticoagulant EDTA type [3, 4]. Its values vary according to age, gender and ethnicity. In dermatology, If the clinical examination is essential, the blood count provides important information for the diagnosis and monitoring of patients. It is a systematic assessment requested during the management of serious dermatosis. The blood count is used to evaluate the impact of dermatosis on the immune defense mechanism or to link an infectious syndrome to a defensive cell defect. In the follow-up of the treatment, the hemogram is an index of the evolution of the dermatosis and the general state of the patient. The blood count is the refore an examination that is of diagnostic and prognostic value in the management of dermatological conditions. A study conducted in Burkina Faso between January 1, 1995 and December 31, 1996 on pediatric dermatosis, found among the 43 children included, anemia in 13 children (30.2\%) and hypereosonophilia in 16 children (16, $3 \%$ ) [5]. On the other hand, the frequency of disorders of a blood count during dermatological affections is not sufficiently reported. Very little study has been conducted on the question from which the interest of this study whose objective is to determine the place of the hemogram in the management of dermatosis in hospitalized patients of the CNAM.

\section{Patients and Methods}

\subsection{Study Framework}

This study was conducted in the Department of Dematology and Venetology of the National Center for Support of Disease Control (CNAM). It is located in the center of Bamako in Djicoroni-para neighborhood near the Beret Red Military Camp. It is one of the largest hospitals in Mali. it is a reference structure for the treatment of dermatological conditions in the country.

\subsection{Type of Study Our Study}

This is a cross-sectional retrospective study from January 2003 to April 2006 on the descriptive analysis of the records of hemogram at the hospitalized patients in the dematology department of the CNAM.

\subsection{Study Period}

Our study was carried out from 1st January 2015 to 31 st
December 2017, ie 3 years.

\subsection{Ethical Consideration}

The free and informed consent of all our patients was obtained before their inclusion and approval of the study protocol was obtained from institutional 'Ethic Committee' at National Support Center for Disease Control.

\subsection{Sample Collection and Processing}

During our study period, the hemogram was performed in 133 hospitalized patients and 112 cases according to our definition were included in this study. Included in our study were all hospitalized patients who had blood counts regardless of sex and age

\subsection{Statistical Analysis}

The data was collected on a survey sheet. The processing and the statistical analysis of the data were carried out using the software EPI INFO 6.04 French version and the Seizures with the software Microsoft Word.

\section{Results}

At the end of our recruitment, we collected a total of 133 files according to our definition. The abnormalities of the blood count were observed in 112 patients, ie $84.2 \%$ of the cases. Females represented $51.9 \%$ of cases and males $48.1 \%$ of cases (Figure 1). The age of the patients ranged from 2 years to 90 years with an average age of 54.34 years. The age group of 60 and over accounted for $44.6 \%$ of cases, while the age group of 45 at age 59 represented $22.5 \%$ of cases. Among the hematological disorders observed:

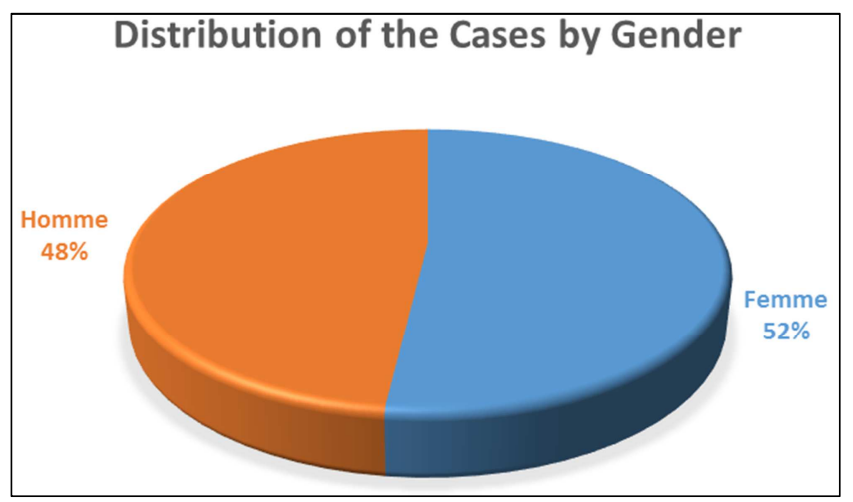

Figure 1. Distribution of the cases by Gender.

Anemia accounted for $86.6 \%$ of cases (Table 1). It was hypochromic and microcytic in $80.4 \%$ of cases, normochromic and normocytic in $16.5 \%$ of cases and macrocytic normochromic in $3.1 \%$ of cases. This anemia was associated with chronic ulceration in almost $100 \%$ of cases, autoimmune bullous dermatosis (Pemphigus and Bullous Pemphigoid) in $72.7 \%$ of cases, erysipelas in $81.8 \%$ of cases, severe toxidermias in $75 \%$ of cases. cases, erythroderma in $60.4 \%$ of 
cases, cutaneous carcinoma in $87.2 \%$ of cases (Table 2). Leukocytosis accounted for $59.8 \%$ of cases (Table 1). This leukocytosis was predominantly neutrophilic in $44.6 \%$ of cases, eosinophilic in $16.5 \%$ and lymphocytosis was observed in $14.6 \%$ of cases. Lymphocytosis with the collapse of CD4 T lymphocyte count was observed in HIV-positive patients in $67.4 \%$ of cases. This leukocytosis was associated with chronic ulcerations in $44.2 \%$ of cases, with autoimmune bullous dermatoses (Pemphigus and Pemphigoid bullosa) in $81.6 \%$ of cases, with erysipelas in $63.6 \%$ of cases, with severe toxicidermias in $74.6 \%$ of cases. $5 \%$ of cases, erythroderma in $60.2 \%$ of cases, skin carcinoma in $66.3 \%$ of cases. Some lepromatous and tuberculous cutaneous patients had monocytosis. Thrombocytopenia was observed in $28 \%$ of cases and was associated with chronic ulcerations in $15.4 \%$ of cases, erysipelas in $31.6 \%$ of cases and cutaneous carcinomas in $56.7 \%$ of cases. 11 cases of pancytopenia, or $8.27 \%$, were related to cutaneous carcinomas.

Table 1. Distribution according to the anomalies of the hemogram (the anomalies were defined starting from the norms of the laboratories).

\begin{tabular}{lll}
\hline Abnormalities & Effective & Pourcentage\% \\
\hline anemias & 97 & 86.6 \\
Hyperleukocytosis at PNN & 50 & 44.6 \\
Hyperleucocytosis at PNE & 17 & 15.2 \\
Hyperlymphocytosis & 13 & 14.6 \\
Neutropénia & 1 & 0.9 \\
Hyperplaquettosis & 4 & 3.57 \\
Thrombopenia & 11 & 9.82 \\
Total & 112 & 100 \\
\hline
\end{tabular}

Table 2. Summary of hemogram abnormalities associated with dermatosis.

\begin{tabular}{|c|c|c|c|c|c|c|c|c|c|c|c|}
\hline \multirow{2}{*}{$\begin{array}{l}\text { Dermatosis Abnormalities of } \\
\text { the hemogram } \\
\text { Anemias }\end{array}$} & \multicolumn{2}{|c|}{ chronic ulcer } & \multicolumn{2}{|c|}{$\begin{array}{l}\text { Bullous dermatosis } \\
\text { Autoimm }\end{array}$} & \multirow{2}{*}{$\begin{array}{l}\text { Erysipelas } \\
81.8\end{array}$} & \multicolumn{2}{|c|}{$\begin{array}{l}\text { Serious } \\
\text { Toxidermy }\end{array}$} & \multicolumn{2}{|c|}{ Erythroderma } & \multicolumn{2}{|c|}{$\begin{array}{l}\text { cutaneous } \\
\text { carcinomas }\end{array}$} \\
\hline & 112 & 100 & 81 & 72.7 & & 84 & 75 & 67 & 60.4 & 97 & 87.2 \\
\hline Hyperleucocytosis & 49 & 44.2 & 91 & 81.6 & 63.6 & 83 & 74.5 & 67 & 60.2 & 74 & 66.03 \\
\hline Neutropenia & 10 & 9.11 & 2 & 1.7 & 5.01 & 19 & 17.01 & 23 & 21.01 & 65 & 58.03 \\
\hline Hyperplaquettosis & 16 & 14.52 & 1 & 0.88 & 11.01 & 1 & 0.89 &, 7 & 6.12 & 3 & 2.68 \\
\hline Thrombopenia & 17 & 15.4 & 1 & 0.89 & 31.6 & 10 & 9.1 & 3 & 3.2 & 63 & 56.7 \\
\hline
\end{tabular}

\section{Discussion}

We performed a cross-sectional, descriptive study of the blood count in hospitalized patients in the dermatology department of the CNAM. During this study 133 cases according to our definition were included on which 112 had an abnormal blood count or $84.2 \%$ of cases. This high frequency of haematological disorders confirms the importance of the blood count in the management and monitoring of hospitalized dermatological patients. It must be practiced before any therapy. Females dominated our study in $51.9 \%$ and the average age was 54.34 years. This could be explained by the high frequency of factors favoring the occurrence of serious dermatoses in women such as depigmentation, sedentary lifestyle and obesity. The predominance of the elderly could be explained by the fragility of the skin and the immune system due to aging. Y Fofana et al and A Mahe have made the same observation $[6,7]$. Biologically, anemia was the most observed haematological disorder, accounting for $86.6 \%$ of cases. It has been observed in all dermatological patients hospitalized. This result could be explained by the importance of the inflammatory that can cause many dermatoses, the degree of hydroelectrolyte loss by fragility of the cutaneous barrier. Hyperleukocytosis was observed in $59.8 \%$ of cases. This result is superior to that of Traore et al which provided $30.2 \%$ of anemia in children. This leukocytosis was much more related to infectious dermatoses such as superinfected chronic ulcerations, necrotizing bacterial dermohypodermatitis and necrotizing fasciitis with bacteria producing substances that are involved in the chemotaxis of polynuclear (Figure 2). This confirms data from the literature that leukocytes, especially neutrophils, are involved in bacterial infections [8, 9]. Hyperlymphocytosis was observed in $14.6 \%$ of cases and was related to inflammatory dermatoses such as toxidermies (Figure 3), autoimmune bullous dermatoses. This is explained by the large production of antibodies during these dermatosis. Some lepromatous and tuberculous skin patients had monocytosis. This monocytosis was reaction and due to reversion reactions by regain of cellular immunity. Thrombocytopenia was observed in $28 \%$ of cases and this thrombocytopenia was linked to the microsubition of certain dermatoses especially tumoral (cutaneous carcinomas). Pancitopenia was observed in 11 patients, ie $8.23 \%$. This pancitopenia was related to cutaneous carcinomas (basal cell and squamous cells) (Figure 4). People living with hiv / aids had lymphopenia with a CD4 $\mathrm{T}$ cell count of less than $250 \mathrm{~mm} 3$ in $67.4 \%$ of cases. this result indicates severe immunodepression in these patients. This result is comparable to that of Zannou $\mathrm{DM}$ et al who respectively found a CD4 $<250 / \mathrm{mm} 3$ in $59.6 \%$ and $50.91 \%$ and $54.2 \%$ of the cases [10].

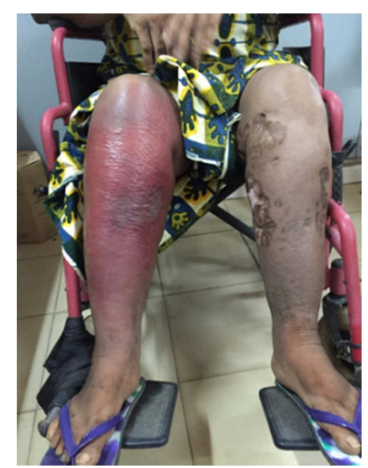

Figure 2. Inflammatory, microcytic, normochromic anemia in an inpatient patient with erysipelas. 


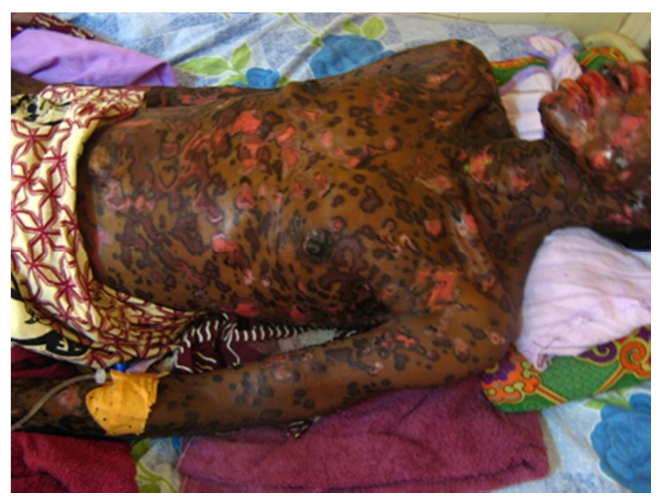

Figure 3. Serious toxicosis (Lyell syndrome) with Hematologic result.

erythrocytes 3750000 , hemoglobin $8.8 \mathrm{~g} / \mathrm{dl}$, hematocrit $26.2 \%$, TGMH 23pg Evidence of hypochromic microcytic anemia

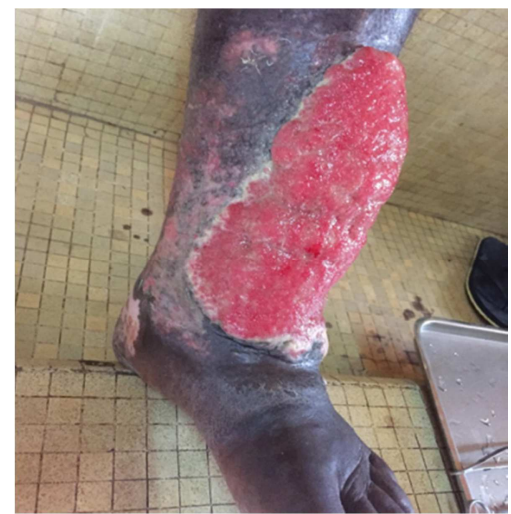

Figure 4. A basal cell carcinoma that presents in its hemogram a pancytopenia.

\section{Conclusion}

The blood count remains the essential biological examination for the management and monitoring of severe dermatosis requiring hospitalization. This study allowed us to identify the disorders of the most frequent hemogram during the dermatoses and their frequency. Our results are consistent with literature data in the majority of cases. Finally, this work could be a prerequisite for further studies aimed at elucidating its impact on the evolution of dermatological disease.

\section{Conflict of Interest}

Authors declare that there is no conflict of interest.

\section{Acknowledgements}

We would like to express their gratitude to the patients for their participation in this stady. We are indebted to the staff Dermatology of CNAM, Faculty of Medicine and Odontostomatology, university of the sciences, Technics and Technology, Bamako, and staff of Biological laboratory of the National Institute for Public Health Research, of Bamako for their assistance.

\section{References}

[1] A BISSEY A., MIGNONSIN D., VILASCO B., BONDURAND A., Contribution of the hemogram in the classification of anemias. Afr Black Med., 38 (11): 769-772, 1991.

[2] BERNARD J., LEVY J. P., VARET B., CLAUREL J. P., RAIN J. D. SULTANT Y.,. Hematology Abstracts, 9th edition; Paris: Manson. 1998.

[3] SWAANENBURG JCJM, RUTTEN WPF, ACJM HOLDRINET, VANSTRIK $R$. The determination of references for hematologic parameters using results obtained from patient populations. Am J Clin Pathol., 88: 182-91, 1987.

[4] French Society of Hematology, College of French Hematologists. Diagnosis, prognosis, treatment and surveillance of polycythemia. Consensus Conference, June 21, 1993. Paris: ANDEM, 1993.

[5] . Traoré A and col. Infectious dermatoses of the child in a dermatology department in a tropical environment (Burkina Faso). Burkina Medical Journal., 12 n02: 40-43, 1998.

[6] Y Fofana, A Dicko, 2, K Tall, et al. The reasons for hospitalization in children under 16 in Bamako. Journal of the Society of Clinical Biology of Benin., No. 027; 74-77, 2017.

[7] MAHE A., KEITA S., Faye O. et al. Handbook for the management of common skin diseases in Mali., p25, 2004.

[8] DALLMAN PR, YIP R, JONHSON C. Prevalence and causes of anemia in the United States, 1976 to 1980 . Am J Clin Nutr., 39: 437-45, 1984.

[9] PIERARD g. E., E. CAUMES, FRANCIMONT C., ESTRADA J. A. Tropical Dermatology, Brussels, Editions of the University of Brussels., p 605, 1993.

[10] SANOU DM, KINDE-GAZARD D, VIGAN J, ADE G, SAHONOU JJ, ATADOKPEDE $F$ and al. Clinical and immunological profite of HIV infected patients in Cotonou, Benin Med Mal Infect., 34: 225-28, 2004. 